\title{
da necessidade de interrogar o pensamento: gestos sobre a infância no tempo escolar
}

\author{
luciana pacheco marques ${ }^{1}$ \\ universidade federal de juiz de fora, brasil \\ cristiane elvira de assis oliveira ${ }^{2}$ \\ universidade federal de juiz de fora, brasil \\ núbia schaper santos ${ }^{3}$ \\ universidade federal de juiz de fora, brasil
}

resumo

Apresentamos neste artigo uma discussão sobre gestos produzidos a partir do verbete infância na interface com a experiência do tempo escolar. Trata-se de uma discussão tecida no interior do Núcleo de Estudos e Pesquisas em Educação, em especial, do Grupo Tempos da Faculdade de Educação da Universidade Federal de Juiz de Fora/MG. Ao longo da história, o tempo foi discutido de diversas formas e ainda o é, bem como a infância, conceitualmente construída em decorrência das influências sociais, políticas, religiosas, culturais. No intento de "iniciar-se no pensar", interrogamo-nos sobre quais formulações teóricas têm assentado o verbete infância na interface com o tempo escolar no campo da educação? Defendemos a tese central de que a infância, em um recorte ocidental, tem sido apresentada nas produções ainda como tempo social. é recente o movimento de considerar a infância como acontecimento, experiência, contrapondo-se à ideia da infância como etapa da vida. Em decorrência disso, considerar a infância relacionada à tensão entre o tempo social e o tempo como intensidade do presente, imprime a necessidade de gestos pedagógicos que pensem esta tensão e, assim, considerem as crianças da/na atualidade, estreitando as suas relações com a escola, com o conhecimento e com a vida. Para iluminar as questões costuradas de nossas inquietações, elegemos autores como Agamben, Leal, Bakhtin/Volochinov, Kohan, Vieira, Bento e Meneghel, Kramer, Borba, que se debruçaram na díade infância e educação. Para problematizar a categoria tempo, dialogamos com Santo Agostinho, Oliveira, Marques C. e Marques L, Skliar. A leitura dos nossos interlocutores e a nossa escuta com/para a escola puderam subsidiar o pensamento de que podemos inventar caminhos não somente imaginados como possíveis na perspectiva de refletir tempo, infância, experiência e escola sobre outras bases. A interrogação e não a convicção possibilita o sentido do conhecimento na materialidade das nossas práticas, produzidas dentro/fora da universidade. Estes são assuntos pouco privilegiados nas matrizes curriculares e disciplinas que abordam a questão das crianças, suas infâncias e temporalidades.

palavras-chave: infância; tempo; educação.

\section{from the need to question thought: child gestures on school time}

abstract

We present in this article a discussion about gestures produced from the childhood entry in the interface with the experience of school time. It is a discussion woven inside the center for studies and research in education in particular, the times group of the faculty of

\footnotetext{
${ }^{1}$ E-mail: luciana.marques65@gmail.com

2 E-mail: cristianeelvira@yahoo.com.br ${ }^{3}$ E-mail: nubiapsiufjf@gmail.com

${ }^{3}$ E-mail: nubiapsiufjf@gmail.com
} 
education of the federal university of Juiz de Fora/MG. Throughout history, time has been discussed in various ways and still is, as well as childhood, conceptually constructed as a result of social, political, religious, and cultural influences. In the attempt to "start thinking", we ask ourselves about what theoretical formulations have been based on childhood at the interface with school time in the field of education? We defend the central thesis that childhood, in a western cut, has been presented in productions still as social time. It is a recent movement to consider childhood as an event, experience, as opposed to the idea of childhood as the stage of life. As a result, considering infancy related to the tension between social time and time as intensity of the present, implies the need for pedagogical gestures that think this tension and, thus, consider the children of the current, narrowing their relations with the school, with knowledge and with life. To enlighten the issues sewn from our concerns, we chose authors such as Agamben, Leal, Bakhtin/Volochinov, Kohan, Vieira, Bento and Meneghel, Kramer, Borba, who focused on childhood and education. In order to problematize the time category, we dialogued with St. Augustine, Oliveira, Marques C. and Marques L, Skliar. The reading of our interlocutors and our listening with/to the school could subsidize the thought that we can invent ways not only imagined as possible with the perspective of reflecting time, childhood, experience and school on other bases. The interrogation, not the conviction, enables the sense of knowledge in the materiality of our practices, produced inside/outside the university. These are underprivileged subjects in curriculum matrices and disciplines that address the issue of children, their childhoods and temporalities.

keywords: childhood; time; education.

\section{la necesidad de interrogar el pensamiento: gestos sobre la infancia en el tiempo escolar}

\section{resumen}

En este artículo se presenta una discusión sobre gestos producidos a partir de la infancia en conexión con la experiencia del tiempo escolar. Se trata de una discusión tejida en el interior del Núcleo de Estudios e Investigaciones en Educación, en especial, del Grupo Tiempos de la Faculdade de Educação da Universidade Federal de Juiz de Fora/MG. A lo largo de la historia, el tiempo fue discutido de diversas formas y aún lo es, así como la infancia, conceptualmente construida como consecuencia de las influencias sociales, políticas, religiosas, culturales. En el intento de "iniciarse en el pensar", nos preguntamos ¿Qué formulaciones teóricas han asentado la infancia en conexión con el tiempo escolar en el campo de la educación? Defendemos la tesis central de que la infancia, en un recorte occidental, ha sido presentada en las producciones aún como tiempo social. Es reciente el movimiento de considerar la infancia como acontecimiento, experiencia, contraponiendose a la idea de infancia como etapa de la vida. En consecuencia, considerar la infancia relacionada a la tensión entre el tiempo social y el tiempo como intensidad del presente, imprime la necesidad de gestos pedagógicos que piensen esta tensión y, así, consideren a los niños de la actualidad, estrechando sus relaciones con la escuela, con el conocimiento y con la vida. Para iluminar e nuestras inquietudes, elegimos a autores como Agamben, Leal, Bakhtin/Volochinov, Kohan, Vieira, Bento y Meneghel, Kramer, Borba, que se inclinaron en la díada infancia y educación. Para problematizar la categoría tiempo, dialogamos con San Agustín, Oliveira, Marques C. y Marques L, Skliar. La lectura de nuestros interlocutores y nuestra escucha con / a la escuela dieron base al pensamiento de que podemos inventar caminos no sólo imaginados como posibles al reflexionar sobre tiempo, infancia, experiencia y escuela sobre otras bases. La interrogación y no la 
convicción posibilita el sentido del conocimiento en la materialidad de nuestras prácticas, producidas dentro / fuera de la universidad. Estos son asuntos poco privilegiados en las matrices curriculares y disciplinas que abordan la temática de los niños, niñas, sus infancias y temporalidades.

palabras clave: infancia; tiempo; educación. 
da necessidade de interrogar o pensamento:

gestos sobre a infância no tempo escolar

O novo, no tempo - como na educação e em quase todas as outras coisas -, é questão de experiência. De atenção. De escuta.

De inícios imprevistos, interruptores, criadores. De pensar inícios e de iniciar-se no pensar. A cada vez. Sempre, com a intensidade da primeira vez. Com a intensidade da [...] infância.

(KOHAN, 2008, p. 61).

\section{nossas pesquisas}

Nossos estudos na área da educação e diversidade no/do grupo de pesquisa núcleo de estudos e pesquisas em educação e diversidade - neped - da faculdade de educação da universidade federal de juiz de fora têm sido direcionados para a compreensão das diferenças, tanto no que se refere aos fundamentos históricos, filosóficos, sociológicos que implicam na atualidade numa outra forma dos homens e mulheres serem, estarem e se relacionarem no e com o mundo, como também nos reflexos de toda essa mudança na e para a educação. Uma das linhas de pesquisa do núcleo - cotidiano escolar e diversidade - tem como pano de fundo o deslocamento do dado do universal da modernidade para o do múltiplo da atualidade, através da análise das categorias conhecimento, tempo, espaço e sujeito. Temo-nos aprofundado nas últimas pesquisas na temática tempo.

Nos projetos tempos na escola, tempo: estado da arte na educação, temporalidades no/do cotidiano escolar, cotidiano escolar: tempos e práticas realizamos estudos sobre o tempo na relação com temáticas que perpassam o cotidiano escolar. Enveredamonos pela necessidade de conversar. Necessidade de interrogar, de inventar, de improvisar. De buscar aquilo que não diga o mesmo sobre o já sabido. “Não mais pensamentos, mas a experiência do pensar. Não mais leituras, mas a experiência de ler. Não mais escritos, mas a experiência de escrever (Leal, 2011, p. 56).

A palavra experiência, nos nossos estudos e pesquisas, está ancorada em Larrosa (2002, p. 21), quando nos diz que é necessário pensar a díade experiência/sentido na relação com o campo da educação. Para ele, experiência é 
"o que nos passa, o que nos acontece, o que nos toca"; e em Agamben (2005) quando revela que experiência e infância são condições de possibilidade de uma existência humana, não importando a idade. Sem ela (a infância) não teríamos como passar da natureza à cultura. A infância é condição da história e da experiência.

Os estudos e as pesquisas nos permitiram (re)escrever a história da questão do tempo no grupo tempos. Apreciamos os estudos feitos da questão da infância na relação com o tempo escolar a partir de autores(as) que se dedicaram a essa discussão (AGAMBEN, LEAL, BAKHTIN/VOLOCHINOV, KOHAN, VIEIRA, BENTO E MENEGHEL, KRAMER, BORBA, SANTO AGOSTINHO, OLIVEIRA, MARQUES C. E MARQUES L, SKLIAR). Nesta direção, temos o objetivo de apresentar os gestos produzidos sobre a infância na interface com o tempo escolar.

O verbete gesto denota um modo de produção de sentido, a partir do que se revela. Para AGAMBEN (2008, p. 12-13):

o que caracteriza o gesto é que, nele, não se produz, nem se age, mas se assume e suporta. Isto é, o gesto abre a esfera do ethos como esfera mais própria do homem. [...] se o fazer é um meio em vista de um fim e a práxis é um fim sem meios, o gesto rompe a falsa alternativa entre fins e meios que paralisa a moral e apresenta meios que, como tais, se subtraem ao âmbito da medialidade, sem por isso tornarem-se fins. [...] o gesto é a exibição de uma medialidade, o tornar visível um meio como tal. Este faz aparecer o ser-num-meio do homem e, desse modo, abre para ele a dimensão ética (AGAMBEN, 2008, p. 12-13, grifo do autor).

A questão que se coloca é: que gestos apresentam as(os) pesquisadoras(es) sobre a infância?

\section{infâncias, crianças}

Disse Guimarães Rosa (2005), em 1962, no livro de contos intitulado de primeiras estórias: “não gosto de falar em infância. É um tempo de coisas boas, mas sempre com pessoas grandes incomodando a gente, intervindo, estragando os prazeres. Recordando o tempo de criança, vejo por lá excesso de adultos, todos eles, os mais queridos, ao modo de policiais do invasor, em terra ocupada". Ao trazer uma passagem autobiográfica, o autor traz também a complexidade da 
discussão sobre as infâncias e temporalidades. Não se trata de um tempo apenas pueril, de prazer e de leveza. Diz de certo desconforto pela presença significativa de adultos a vigiar e guiar os passos dos que não sabem, não podem. A narrativa de rosa abre o caminho para a desconstrução do discurso normatizador pedagógico/psicológico, que em muitos casos, preconiza a noção da infância ideal, sem ranhuras, linear. Enuncia, de maneira singular, o paradoxo inerente à memória de um adulto, já distante do vivido, a infância do acontecimento, do mal-estar, do inescapável.

As discussões em torno da infância envolvem questões e noções teóricas, suscitam tensões políticas e trazem desafios na/para as práticas cotidianas. A palavra infância se "expressa como algo que não sabemos, que escapa a nossas verdades, que se reveste de novos sentidos a cada vez que é pronunciada" (LEAL, 2011, p. 19).

Para Bakhtin/Volochinov (1988), o sujeito não se constitui apenas pela ação discursiva, mas todas as atividades humanas, mesmo as mediadas pelo discurso, oferecem espaço de encontros de constituição de subjetividade, pela constituição de sentidos. Assim, “as palavras são tecidas a partir de uma multidão de fios ideológicos e servem de trama a todas as relações sociais em todos os domínios" (BAKHTIN/VOLOCHINOV, 1988, p. 14).

Observamos que ao longo da história foram construídos diversos gestos sobre as infâncias, modos diferentes de pensá-las. No nascimento da palavra infância esta recebeu uma denotação de falta, ausência e incapacidade, o que desencadeou reflexos até hoje. “A percepção da infância desde a perspectiva da falta iluminou - e ainda ilumina - os mais nobres ideários pedagógicos, discursos filosóficos e saberes científicos da modernidade" (KOHAN, 2008, p. 41).

$\mathrm{Na}$ idade moderna se passou a ter maiores cuidados com a criança, a família ocidental europeia ganhou importância e valor, assim o sentimento de infância surgiu com o sentimento de família. Neste contexto, a educação era destinada apenas para crianças nobres. A partir do século XX, áreas de conhecimento como psicologia, medicina, antropologia, sociologia, filosofia e 
pedagogia iluminaram a infância e a criança como potentes campos de investigação. Recentemente, a proposição de que a infância é uma categoria que se articula a cultura e que está relacionada e necessariamente atrelada ao contexto sócio-histórico ganha relevo (VIEIRA, 2010). A criança, pouco visível para a ciência, passa a ser considerada um "sujeito ativo que também influencia, modifica e constrói este meio" (BENTO; MENEGHEL, 2010, p. 2), no qual vivemos e nos relacionamos. Em decorrência disso, Kramer (1995) salientou que a noção de infância não existiu sempre e de uma mesma forma. Ela apareceu com a modernidade capitalista.

Neste sentido, os gestos sobre a infância são determinados historicamente de acordo com as modificações sofridas pela sociedade. "Isto implica que a concepção de infância como uma categoria única e permanente não é possível" (VIEIRA, 2010, p. 3).

A sociologia da infância vem pautando, de maneira contundente, oposição à ideia de infância alicerçada no modelo adultocêntrico europeu de criança e infância. Desde a década de 1990, a sociologia da infância vem se consolidando no Brasil na busca por constituir um novo paradigma como área de conhecimento e campo de pesquisa, no que se refere à construção social da infância, reivindicando para a criança um lugar de sujeito e de protagonismo na história e na cultura. Busca-se, no conjunto de formulações teóricas dessa abordagem, romper com a visão reducionista da criança como um ser em devir que futuramente se tornará um adulto, com a noção de que a criança é considerada "pelo que não é e pelo que lhe falta em relação ao adulto - in-competente, i-matura, i-racional" (BORBA, 2010, p. 1).

[...] a sociologia da infância propõe uma virada paradigmática, ou seja, revelar a criança na sua positividade, como ser ativo, situado no tempo e no espaço, nem cópia nem o oposto do adulto, mas sujeito participante, ator e autor na sua relação consigo mesmo, com os outros e com o mundo. Com base nessa premissa, postula que a infância e as crianças devem ser estudadas na sua alteridade e pelo valor que têm em si mesmas, e não indiretamente ou passivamente através de outras categorias da sociedade, como a família ou a escola (BORBA, 2010, p. 1). 
A sociologia da infância propõe a valorização das crianças, considerando-as potentes para interpretar e agir no mundo como produtoras de cultura, problematizando a visão adultocêntrica a respeito delas. Possibilita reflexões, fazendo-nos construir/reconstruir nossa visão a respeito da criança e da infância. As formulações teóricas do campo da sociologia da infância têm possibilitado reinventar e criar instrumentos metodológicos que possibilitem aproximação com aqueles e aquelas com pouca idade, mas que têm condições de pensar, narrar, explorar, atuar, conhecer o/no mundo em que vivem. Em síntese, este aporte teórico reverbera no campo metodológico, principalmente na problematização das éticas das pesquisas com as crianças. Além disso, tem viabilizado realizar desconstruções nos gestos sobre a infância, uma vez que de acordo com essa perspectiva, a infância só tem condição de existência como categoria se for pensada no plural.

Por essa via, a ideia da criança como aquela que tem voz não somente para dizer aquilo que queremos ouvir, aparece bastante sólida nas produções acadêmicas, ainda que as pesquisas sobre as crianças e suas infâncias sejam recentes e que essas formulações não alcancem a vida vivida, o cotidiano das atividades, nas quais as crianças estão inseridas, como a escola, para citar um exemplo. Essas suposições sobre a infância como uma experiência da vida e não somente como uma etapa da vida deve-se em parte aos estudos da filosofia, da sociologia, da antropologia, da psicologia, em especial, da literatura. a imagem da infância idílica se distancia na mesma velocidade em que construímos outro discurso para o espaçotempo da/na/para as infâncias bastante diferentes daquele anunciado pelo romantismo rousseauniano ${ }^{4}$.

Pensando um pouco mais a infância, Kohan (2008, p. 45) apresenta que, para os filósofos Platão e Aristóteles, “a infância deixa de ser apenas uma etapa da vida para representar, de um modo mais geral e paradigmático, uma possibilidade evolutiva do ser humano". Desta forma, a infância é a própria

\footnotetext{
${ }^{4}$ Ao propor uma filosofia libertária, Rousseau foi um dos principais representantes do iluminismo francês. Preocupou-se com os processos educativos e ponderou em suas obras que a criança distancia-se de duas virtudes naturais na medida em que mantém contato com a vida social.
} 
condição de ser tocado. Está numa temporalidade sem cronologia, sem antes e depois. Ela é o nascimento que se estende à vida toda e não é apenas o acontecimento biológico do parto. Nas palavras deste autor (KOHAN, 2008, p. 47):

então, sempre nos nasce uma criança, a vida toda. Porque a infância é o acontecimento que impede a repetição do mesmo mundo, pelo menos a sua possibilidade, um novo mundo em latência. Somos nascidos a cada vez que percebemos que o mundo pode nascer novamente e ser outro, completamente distinto daquele que está sendo. $\mathrm{O}$ nome de uma faculdade chamada criação, transformação, revolução, isso é a infância.

Kohan (2008) faz uma relação entre infância, experiência e linguagem. Na infância cronológica, no seu início, há uma ausência de linguagem, mas que posteriormente se inicia. Na adultez ocorre uma ausência da possibilidade de se inscrever na linguagem, porque já se encontra dentro dela. Dessa forma, “a aprendizagem da linguagem, está ligada a uma disposição infantil: se abandonamos a infância, abandonamos também a possibilidade de entrar na linguagem, seja porque renunciamos a essa possibilidade, seja porque já estaremos dentro dela" (KOHAN, 2008, p. 48). Neste contexto, a infância está na condição da/na experiência e da/na história.

Num certo sentido, estamos sempre aprendendo a falar (e a ser falados), nunca "sabemos" falar (ou somos "sabidos" pela linguagem) de forma definitiva, nunca acaba nossa experiência na e da linguagem. Nessa mesma medida, o ser humano não pode renunciar à infância. Se ele nascesse sem infância, com a linguagem nos genes, seria pura natureza, língua morta, repetidor sempiterno de mesmo; se ele renunciasse à infância em nome da adultez perderia a capacidade de se inventar, de encontrar novos inícios, de abrir a possibilidade de falar para criar um novo mundo e não apenas para reproduzir o mesmo mundo (KOHAN, 2008, p. 48).

Infância e experiência são possibilidades da existência humana, não importando a idade. A infância é uma possibilidade de intensificar uma relação com o tempo, instaurando um outro. Associa-se a infância ao tempo aiónico. $\mathrm{O}$ tempo aión é o tempo das durações e das intensidades. Como diz Kohan (2008, p. 49): “aión, o tempo infantil, é o tempo circular, do eterno retorno, sem a sucessão consecutiva do passado, presente e futuro, mas com a afirmação intensiva de um outro tipo de existência". Dessa forma, a infância está relacionada a uma outra 
temporalidade diferente da cronológica; a infância é uma imagem da novidade, da criação, da transformação, sempre presente, de um novo ser (KOHAN, 2008).

Considerar a dimensão da infância é pensar nossa relação com o tempo e com o que somos, possibilitando, assim, observar e conversar com a criança a respeito da escola, levando-nos a refletir nossas práticas cotidianas. a noção de infância presente no nosso discurso diz muito da nossa prática. Pensar outras infâncias é pensar outras temporalidades. A infância supõe outra temporalidade. A infância não lida bem com a cronologia. Kohan (2008) relaciona a infância ao tempo aión. Aión é a criança que brinca. Isso expressa que se estabeleça com a infância uma relação aiónica e que essa relação com a infância seja menos cronológica, buscando-se uma relação brincante com o mundo.

Aprender com a infância. Resgatar, na infância, o que ela tem a nos ensinar. Tornar parte do aprendizado adulto a experiência da infância. Este é um exercício que exige, além do enorme esforço de busca de sentidos, o desprendimento da concepção arraigada, determinante e cronológica do tempo (LEAL, 2011, p. 20).

Nesta mesma direção, Kohan (2008, p. 61) propõe como algo novo uma ruptura na experiência do tempo passando para "uma vida temporal mais intensiva do que extensiva, um outro tempo para o ensinar e o aprender, para além das etapas, das fases, dos desenvolvimentos; um tempo de intensidades mais do que de extensões sucessivas".

Temos até aqui dois gestos sobre a infância. O primeiro trata a infância enquanto construção social, etapa da vida num tempo contínuo sucessivo. A intervenção educacional dá sentido a sua formação, visto que a "educação terá a marca de uma projeção ético-política definida para o bem dos que atualmente habitam a infância, para assegurar seu futuro, para fazê-los partícipes de um mundo melhor" (KOHAN, 2008, p. 52), uma infância com um futuro determinado, previsto, certo. $\mathrm{O}$ segundo gesto traz a infância ligada a outra temporalidade, sendo "pensada mais como condição do que fase, como dimensão mais do que como etapa. Assim ela é colocada ao lado da experiência, do acontecimento, da ruptura da história, da revolução, da resistência e da criação" (KOHAN, 2008, p. 
52). Nesta abordagem, a infância não pode ser universalizada ou antecipada.

Ligada a esta perspectiva, temos o devir-criança, conceito criado por Deleuze e citado por Kohan (2008, p. 50): “devir é se encontrar no acontecimento, no movimento, na multiplicidade, com algo sem passado, presente ou futuro; algo sem temporalidade cronológica, mas com geografia, com intensidade e duração próprias".

E quais gestos têm se apresentado na história em relação ao tempo?

\section{tempo, temporalidades}

Santo agostinho, em sua obra confissões, apresenta uma "abordagem do tempo mergulhada no mistério como aquilo que se sabe mas não consegue dizer" (BORNHEIN, 2003, p. 93). Ou seja, quando não se pergunta sobre o tempo, sabemos o que ele é, no entanto, quando nos perguntam, não sabemos responder. Então, o porquê de não conseguirmos explicar por meio de palavras o que vem a ser o tempo?

Sabemos que ao longo da história, o tempo foi concebido de diversas formas e ainda o é. Diversos autores, como Santo Agostinho, Heri Bergson, Nobert Elias, Paul Ricoer, para citar alguns, possuem seus gestos sobre o tempo, numa lógica ocidentalizada. Dessa forma, podemos pensar o tempo por meio de três gestos: o tempo na antiguidade - cíclico; o tempo na modernidade - linear; e o tempo na atualidade - simultâneo; que, apesar de datados historicamente, nos afetam pelas formas como nos relacionamos com o tempo.

$\mathrm{Na}$ antiguidade, o tempo se pautava nos ciclos naturais. As principais atividades produtivas estiveram centradas na caça, na coleta, no cultivo e no pastoreio, concomitante a isso, havia os ciclos essenciais para a sobrevivência vinculados aos dias, às noites e às estações do ano. Neste período, não havia necessidade de dividir o dia em partes, pois as atividades econômicas estavam articuladas aos ciclos diário e sazonal. Assim, os ciclos naturais regiam as comunidades humanas. O tempo servia aos homens como meio de orientação no universo social e como regulação de sua existência. 
As sociedades primitivas se organizavam sem o uso dos relógios e utilizavam os fenômenos naturais para harmonizar as atividades dos homens e para adaptá-los a processos que lhes eram externos, da mesma maneira que foram adaptadas, em estágios posteriores, aos símbolos que se repetem no mostrador de nossos relógios.

Num determinado momento da história, no Egito, o dia foi dividido em doze horas, cuja medida baseava-se "segundo o comprimento da sombra de uma varinha fincada verticalmente no chão - o primeiro relógio de sol de que temos notícia. As razões da escolha do número doze não são evidentes" (OLIVEIRA, 2003, p. 40-41).

O relógio de sol passou por grandes modificações a partir da substituição da varinha vertical por uma inclinada, "o gnomon, 'indicador', em grego" (OLIVEIRA, 2003, p. 41). Pelo fato desse relógio não funcionar em dias encobertos ou à noite, houve a necessidade de desenvolver outros recursos para medirem as horas na ausência do sol. Os relógios de água passaram a funcionar como mediadores das horas, a clepsidra (ladrão de água) foi um exemplo. Com o aperfeiçoamento na fabricação de vidros, um novo medidor temporal começou a ser usado, a ampulheta.

De acordo com Oliveira (2003), os sistemas de medida de duração como o relógio de sol, a clepsidra e a ampulheta impediram a invenção do relógio mecânico e os ciclos naturais limitavam as atividades humanas. Por conseguinte, o relógio mecânico foi considerado uma das invenções mais notáveis dos últimos dois mil anos.

O outro gesto se refere ao tempo linear na modernidade, envolvendo o tempo físico. Para discutir esse movimento destaco o fato de que o paradigma da modernidade apresenta-se como uma forma de ver o tempo e de olhar o mundo por meio de representações muito particulares. No pensamento moderno, “o tempo é concebido de forma linear, onde os eventos constituem uma sucessão de acontecimentos cronologicamente ordenados. A relação entre o 'era' (passado), o 'não é mais' (presente) e o 'vir a ser' (futuro) obedece, assim, a uma sucessão 
linear de mudanças" (MARQUES C.; MARQUES L., 2003, p. 226). O presente é a referência para se pensar o passado e o futuro.

O relógio mecânico, com a subdivisão exata da hora em minutos e segundos, passou a regular os fenômenos naturais e a ordenar a vida social e econômica das cidades ao seu redor. "O tempo metrificado fornecido pelos relógios possibilitou que se quantificasse o trabalho humano" (OLIVEIRA, 2003, p. 48). As horas de trabalho do empregado eram convertidas em dinheiro, contribuindo para a mais-valia. Dessa forma, o relógio mecânico foi considerado o artefato fundamental para a configuração do capitalismo moderno.

Neste contexto, a segmentação do tempo em unidades levou a uma revolução no estudo do movimento, abrindo caminho para a concepção do tempo como uma “sucessão linear de unidades de extensão arbitrariamente pequena ou mesmo nula, os instantes" (OLIVEIRA, 2003, p. 45).

No gesto no/do tempo simultâneo na/da atualidade, conforme Marques C. e Marques L. (2003), o tempo linear, conhecido como chrónos, que a modernidade privilegiou, convive e coexiste com o tempo simultâneo, o tempo aión. Assim, não temos apenas a possibilidade de experienciar o tempo chrónos, mas também os tempos aión - que expressa a duração do tempo da vida humana - e kairós - tempo das oportunidades - o que tem possibilitado novas pesquisas com esse foco.

Com isso, temos a possibilidade de experienciar o presente em toda a sua intensidade. O passado se atualiza no presente e o futuro já o estamos vivendo, pois se considerarmos que um minuto após o outro já é futuro... passado e futuro se fundem no presente.

O presente é um presente vivo de que dependem o passado e o futuro: um presente múltiplo, um único tempo em que se concentram todos os tempos, um presente inóspito que se torna hóspede do outro. o tempo é um passado puro, que dá passagem a outro presente: um presente que herda do passado sua própria incompreensão, seus próprios detalhes paradoxais, sua instabilidade e sua permanência. $O$ passado do outro que reverbera, sempre, no presente (SKLIAR, 2003, p. 64).

Este autor (SKLIAR, 2003, p. 47) considera a temporalidade como um estar sendo para que a alteridade não se aprisione na condição e no estado de ser ou não 
ser. um estar sendo como processo, vibração e acontecimento, o que faz com que repensemos "aquele tempo e aquela temporalidade em que o outro era, podia ser, devia ser, não podia ser". estar sendo como experiência implica que nenhum conhecimento já dado sobre o outro pode compreender esse estar sendo.

Podemos considerar, ao estudar o tempo nesses três gestos, que este tem sido concebido, no curso da história, pela forma circular ou linear e atualmente temos como refletir sua simultaneidade.

Diante dessas formas de pensar as infâncias e o tempo, quais olhares sobre a infância na interface com o tempo escolar têm sido apresentados nas produções em educação?

\section{as infâncias na interface com o tempo escolar}

Dos nossos estudos, considerando a circularidade que os discursos apresentam, sempre trazendo à tona os mesmos elementos, elegemos os(as) autores(as) Pinto (2009a, 2009b), Corrêa (2005) e Sant'ana (2009) com os quais iremos dialogar na abordagem das infâncias na interface com o tempo escolar.

Esses autores representam as temáticas que aqui queremos destacar: o tempo do brincar; o tempo ampliado para a escolarização; a organização do tempo em rotina, relacionando a infância ao tempo social.

Pinto $\left(2009 \mathrm{a}^{5}, 2009 \mathrm{~b}^{6}\right)$, na pesquisa que realizou, buscou investigar a condição social da criança na sociedade, tendo como recorte a condição do tempo do brincar no interior de uma escola pública.

Em sua pesquisa, a autora fez as seguintes indagações:

Como está sendo tratada a criança na escola? Como se organiza o tempo e o espaço escolares? Para além de aprender a criança percebe a escola como um espaço também de brincar? Qual o ponto de vista da criança sobre o espaço e o tempo escolares? O que acham do tempo existente para: o recreio, estudar em sala de aula, brincar, fazer amigos, ler, comer, ir ao banheiro? A atual organização do tempo e do espaço escolares está estruturada para receber a criança concreta, hoje concebida como sujeito de direitos? O espaço e o tempo escolares vem sendo organizado de

\footnotetext{
${ }^{5}$ Esta produção de 2003 refere-se à pesquisa em andamento de Pinto.

${ }^{6}$ Esta produção de 2005 apresenta a pesquisa concluída de Pinto.
} 
modo a garantir a participação da criança no seu próprio processo formativo? Enfim, o espaço e o tempo escolares são organizados para as crianças ou com as crianças? Afinal, qual o lugar da infância na escola? (PINTO, 2009a, p. 02, grifos da autora).

As indagações apresentadas nos levam a considerar que a autora concebe a criança como parceira em todas as dimensões que envolvem a organização escolar, crianças como sujeitos capazes, competentes e participantes na organização de seus espaçostempos escolares. Neste sentido, a pesquisadora fez um estudo de como as produções acadêmicas vêm discutindo os tempos e os espaços escolares na sua relação com o tempo e o espaço da infância, elegendo a perspectiva histórica e sociológica para explicar este fenômeno, trazendo algumas considerações sobre como a escola pode vir a se tornar um espaço privilegiado da/para a infância a partir da organização e construção deste espaço e tempo com a participação das crianças, respeitando-as como sujeito de direito.

O objetivo específico da pesquisa foi investigar o ponto de vista das crianças em relação ao tempo e ao espaço do brincar no interior da escola. A autora entrevistou 27 crianças matriculadas de $1^{\mathrm{a}}$ a $4^{\mathrm{a}}$ séries do ensino fundamental em uma escola pública localizada em Florianópolis, gravou e registrou suas falas, de modo a compreender o que pensavam e diziam sobre o tema.

Através dos testemunhos das crianças, a autora percebeu que elas gostavam de estar na escola não só para estudar e aprender, mas também para fazer amigos e estar entre seus pares. Com relação ao tempo para brincar na escola, as crianças disseram que o espaço da escola oportunizava o brincar e novas amizades entre elas, porém queixavam-se do pouco tempo que lhes eram possibilitadas para isso e reivindicavam mais tempo para brincarem no cotidiano escolar.

As crianças ao falarem sobre o espaço para brincar na escola, destacavam as frágeis condições do mesmo. Elas solicitavam espaços organizados e equipados de modo que pudessem favorecer a ludicidade, a brincadeira, a criação, a descoberta e a interação. Tudo indica que quem definia o uso dos espaços e dos tempos na 
escola ainda era o adulto, independente dos desejos e opiniões que as crianças pudessem ter.

Segundo Pinto (2009a, p. 04),

O tempo e o espaço destinados às crianças no interior da escola quando são pensados, planejados e organizados pelo adulto, apresentam uma lógica que nem sempre coincide com a da criança e que, geralmente, serve para conformá-la e discipliná-la, ao invés de emancipá-la.

No entanto, as crianças criavam meios para garantir o tempo do brincar na escola, tais como: chegavam mais cedo para que pudessem brincar antes do início das aulas, faziam da ida ao banheiro uma possibilidade de sair para poderem conversar e brincar com os colegas e aproveitavam os trabalhos em grupos para brincarem escondido da professora.

Os preconceitos dos adultos quanto ao brincar, a relação deste com o fracasso escolar foram internalizados pelas crianças, como por exemplo: na "sala de aula não é lugar de brincar", "quando brinca não aprende". Tais exemplos evidenciam que o brincar na escola ainda é compreendido como sinônimo de bagunça.

A autora apontou para a necessidade de rever a formação das(os) professoras(es), tanto a inicial quanto a continuada, de modo que a criança e a infância sejam contempladas nas discussões realizadas, bem como as questões relacionadas ao tempo do brincar.

A pesquisa realizada por Pinto (2009a, 2009b) nos leva a compreender e considerar o que as crianças dizem e pensam sobre o espaço e o tempo do brincar no interior da escola, possibilitando discutir e repensar a forma como se organiza o espaçotempo no cotidiano escolar. Aqui o foco é na criança enquanto sujeito social e histórico, assim, a infância estaria relacionada ao tempo social.

A pesquisa de Corrêa (2005) apresenta a infância e sua relação com o tempo ampliado na escola. O trabalho da autora teve como locus de pesquisa a escola de período integral, a creche, mas com o foco nas experiências no tempo ampliado das professoras e crianças desta mesma instituição. Seu objeto de estudo foi a 
criança, a infância na relação com a escola de período integral e como o tempo dessa criança é estruturado nessas instituições.

O objetivo de sua pesquisa foi entender as peculiaridades e tensões presentes no espaço das escolas de período integral na educação infantil - as creches, através da interpretação dos depoimentos de três professoras de diferentes escolas em relação aos seus alunos, e da análise do posicionamento das crianças em relação a si mesmas, inseridas neste processo, através de seus desenhos e falas. A autora (CORRÊA, 2005, p. 3) também objetivou: “entender a partir da leitura e análise desses dois sujeitos (professoras e crianças) quem é essa criança. Como ela é vista por si e pelas suas professoras". A abordagem deste trabalho foi a sócio-histórica, concebendo a criança como um ser social ativo.

Corrêa $(2005$, p. 45) destacou que teve o intuito de trabalhar uma questão do senso comum, a qual trata de "como as crianças que freqüentam escolas de período integral influenciam a prática pedagógica e a visão que as professoras têm delas; sobre o seu fazer", buscando verificar se a criança está tendo o seu espaço de infância.

A referida pesquisadora apresentou que na escola de período integral temse produzido uma cultura que não dá espaço para o ócio, para a improdutividade e nem para o lúdico e que a estrutura de organização do tempo e do espaço dessas escolas não estão atendendo às necessidades das crianças. Mas, pensemos: como o tempo nessa escola está organizado? Como crianças e professoras estão experienciando o cotidiano escolar? Que organização física, administrativa e funcional dessa escola atenderiam as necessidades das crianças?

Para Corrêa (2005, p. 18), a educação infantil tem um tempo próprio, sendo "a própria escola que fixa o tempo da infância, criando um tempo social" (p. 18), ou seja, o tempo da infância sendo o tempo de escolarização. Mais uma vez a infância aparece relacionada ao tempo social.

O trabalho de SANT'ANA (2009, p. 01) buscou relacionar a rotina escolar e a infância, tendo o objetivo de refletir a ação da pré-escola no processo de formação da criança por meio da análise da rotina construída. Diante disso, a 
autora questionou: “a organização das atividades no tempo e no espaço cria competências sociais e pessoais favorecedoras de independência e autonomia?".

A rotina é compreendida, pela pesquisadora, como uma disposição temporal da distribuição das atividades presentes no cotidiano da pré-escola, procurando evidenciar os elementos significativos para reflexão das experiências vividas pelas crianças. Na rotina escolar, SANT'ANA (2009) observou que as atividades relativas ao desenvolvimento da linguagem escrita e oral prevalecem dentro e fora da escola, dando indícios de que o brincar não é considerado uma atividade formativa, o que leva a um desrespeito com os tempos das crianças.

O tempo social no cotidiano da escola exprime que a lógica de organização temporal do adulto com a criança supõe alguma forma de controle, do educador e táticas das crianças para com ele. Nesse sentido, a relação entre professor e crianças vive a tensão de duas maneiras de interação com o tempo: “o projeto temporal do professor, marcado pela organização da produção social, e a vivência temporal pela criança, marcada por múltiplos e móveis vínculos com o tempo rítmico das experiências estabelecidas pelas interações" (SANT'ANA, 2009, p. 02). Nesta produção, a infância aparece relacionada à correlação de forças entre ela como tempo social e como temporalidade, ligada ao acontecimento, à experiência.

Parece que a infância tem sido apresentada nas produções ainda como tempo social, etapa da vida num tempo contínuo sucessivo; iniciando-se um movimento de considerar o acontecimento, a experiência, havendo uma correlação de forças entre os gestos da infância enquanto tempo social e ligada à temporalidade.

Estas produções nos levam a (re)pensar as práticas escolarizantes para as crianças na educação, considerando as questões atuais sobre o tempo. Neste sentido, Corazza (2002, p. 191) indaga: “o que faremos com o que fizemos da infância": das childwares; ninjas, sumidas, amarradas, batidas, separadas, traficadas, acariciadas, atacadas, cortadas, anjos, demônios, infectadas, ativas e ocupadas, exploradas? Será que o discurso construído sobre a infância até aqui nos fez crer que havia uma infância ideal e universal? 
Talvez seja mais interessante trabalharmos com os paradoxos do poeta Manoel de Barros. Na obra memórias inventadas (BARROS, 2003) há uma desconstrução da noção de infância. Os poemas que compõem a obra inauguram uma visão interessante sobre a díade tempo/infância: de um lado um desejo de regresso ao estado infantil de ver e descobrir o mundo, de outro, "na busca pelo tempo das travessuras e descobertas que não volta a se repetir, numa tentativa de fazer um percurso contrário ao relógio cronológico, ele torna-se um caçador de achadouros de infância" (LINHARES, 2006, p. 32). A mesma autora segue afirmando que,

a criança, ao ser introduzida no mundo falante, pode ser vista como sujeito ativo, liberado pela palavra e que através dela dá vazão a metáforas e imagens que só habitam a infância, e que constantemente vêm lembrar ao adulto que já existiu um tempo no qual o inventar e o imaginar eram recursos para compreender e interpretar o mundo, de forma a organizá-lo interiormente. No que diz respeito a esse momento de organização diferenciada do mundo que se dá na infância, ocorre a preservação do poético. No anseio de dar continuidade a esse olhar divergente, que se vale de uma maneira modificada de percepção, é que se move barros (LINHARES, 2006, p. 66).

Concebemos a infância como a dimensão da experiência, uma forma de viver/ser/estar no/com o mundo. A infância não é apenas uma etapa do desenvolvimento humano, é a intensidade da duração, expressando a forma como cada um experiencia a vida, já que também ser criança, nessa perspectiva, é algo que independe da idade.

Mais de dez anos se passaram desde que iniciamos os estudos e pesquisas na temática, no entanto, há, como já dito, uma circularidade nas questões. Temos avançado pesquisando com as crianças numa escola que se pretende inovadora em sua forma de organizar o tempo escolar, no projeto escolas inovadoras: usos dos tempos. Temos encontrado inventividade ao considerar na prática pedagógica as temporalidades no experienciar das crianças. 


\section{nossos gestos}

Ao conceber a infância na interface com o tempo escolar, nós professoraspesquisadoras atentamos ao que ela tem e não ao que lhe falta: "como presença e não como ausência, como afirmação e não como negação, como força e não como incapacidade" (KOHAN, 2008, p. 4). Concebemos a infância como a dimensão da experiência, uma forma de viver/ser/estar no/com o mundo. A infância não é uma etapa do desenvolvimento humano, é intensidade, e expressa a forma como cada um experiencia a vida.

Na relação entre a infância e o tempo, não temos apenas a possibilidade de experienciar o tempo chrónos, mas também as noções de tempo aión e kairós. Embora permeie na organização da escola o tempo chrónos, essas temporalidades coexistem no momento presente, no agora. Pensar a escola, desse modo, possibilita outros olhares e sentires no cotidiano, podendo-se experienciar o presente com toda a sua intensidade. O que possibilita "elaborar uma imagem conceitual da infância que permita pensá-la para além da cronologia, desde a lógica da experiência e do acontecimento" (LEAL, 2011, p. 16).

A partir de os estudos e as pesquisas sobre o tempo na produção em educação, encontramos que ora a infância se apresenta como tempo social, etapa da vida num tempo contínuo sucessivo; ora como uma correlação de forças entre o tempo social e o acontecimento.

Considerar a infância relacionada à tensão entre o tempo social e o tempo como intensidade do presente, imprime a necessidade de gestos pedagógicos que pensem esta tensão e, assim, considerem as crianças da/na atualidade, estreitando as suas relações com a escola, com o conhecimento e com a vida.

Podemos inventar caminhos não somente imaginados como possíveis. Podemos estreitar a relação entre tempo, infância, experiência. A interrogação e não a convicção possibilita o sentido do conhecimento na materialidade das nossas práticas, seja o conhecimento produzido dentro ou fora da universidade. Estes são assuntos pouco privilegiados nas matrizes curriculares e disciplinas que abordam a questão das crianças, suas infâncias e temporalidades. Talvez seja 
seguir as palavras de Manoel de Barros em que "desaprender oito horas por dia ensina os princípios".

\section{referências}

AGAMBEN, Giorgio. Infância e história: destruição da experiência e origem da história. Belo Horizonte: Editora UFMG, 2005.

AGAMBEN, Giorgio. Notas sobre o gesto. Artefilosofia, Ouro Preto, n. 4, p. 09-14, jan. 2008.

BAKHTIN/VOLOCHINOV, Mikhail. Marxismo e filosofia da linguagem. 4. ed. São Paulo: Hucitec, 1988.

BARROS, Manoel de. Memórias inventadas: a infância. São Paulo: Planeta, 2003.

BENTO, Karla Lucia; MENEGHEL, Stela Maria. Creches domiciliares como espaço de educação infantil. In: Reunião anual da ANPEd, 26., 2003, Poços de Caldas. Anais eletrônicos. Poços de Caldas: ANPEd, 2003. Disponível em:

<http://www.anped.org.br/reunioes/26/trabalhos/karlaluciabento.rtf>. Acesso em: 19 jul. 2010.

BORBA, Ângela Meyer. As culturas da infância nos espaços-tempos do brincar:

estratégias de participação e construção da ordem social em um grupo de crianças de 4-6 anos. In: Reunião anual da ANPEd, 29., 2006, Caxambu. Anais eletrônicos. Caxambu:

ANPEd, 2006. Disponível em:

<http:/ / www.anped.org.br/reunioes/29ra/trabalhos/trabalho/gt07-2229--int.pdf>.

Acesso em: 19 jul. 2010.

BORNHEIN, Gerd. A concepção do tempo: os prenúncios. In: DOCTORS, Marcio (org.). tempo dos tempos. Rio de Janeiro: Jorge Zahar, 2003. p. 93-107.

CORAZZA, Sônia Mara. Infância \& educação: era uma vez... quer que conte outra vez?

Petrópolis: Vozes, 2002. v. 1. 204p.

CORRÊA, Raquel Romano. Educação infantil no século XXI: a criança em período integral na escola. 2005. 120 f. Dissertação (Mestrado em educação) - Universidade Metodista de São Paulo, São Paulo, 2005.

KOHAN, Walter. Infância e filosofia. In: SARMENTO, Manuel; GOUVEA, Maria Cristina Soares de (orgs.). Estudos da infância: Educação e práticas sociais. Petrópolis: Vozes, 2008. p. 40-61.

KRAMER, Sonia. A política do pré-escolar no brasil - a arte do disfarce. São Paulo: Cortez, 1995.

LARROSA, Jorge. Notas sobre a experiência e o saber da experiência. Revista brasileira de educação, Rio de Janeiro, n. 19, p. 20-28, jan./fev./mar./abr. 2002.

LEAL, Bernardina Maria de Sousa. Chegar à infância. Niterói: EDUFF, 2011. LINHARES, Andrea Regina Fernandes. Memórias inventadas: figurações do sujeito na escrita autobiográfica de Manoel de Barros. 102f. Dissertação de mestrado. Fundação Universidade Federal do Rio Grande. 2006.

MARQUES, Carlos Alberto; MARQUES, Luciana Pacheco. Do universal ao múltiplo: os caminhos da inclusão. In: LISITA, Verbena Moreira S. de S.; SOUSA, Luciana Freire E. C. P. (orgs.). Políticas educacionais, práticas escolares e alternativas de inclusão escolar. Rio de Janeiro: DP\&A, 2003. p. 223-239.

OLIVEIRA, Luiz Alberto. Imagens do tempo. In: DOCTORS, Marcio (org.). Tempo dos tempos. Rio de Janeiro: Jorge Zahar, 2003. p. 33-68. 
PINTO, Maria Raquel Barreto. A condição social do brincar na escola: o ponto de vista da criança. In: Reunião anual da ANPEd, 26., 2003, Poços de Caldas. Anais eletrônicos. Poços de Caldas: ANPEd, 2003. Disponível em:

<http:/ / www.anped.org.br/reunioes/26/ posteres/inesferreirabraganca.rtf>. Acesso em: 19 fev. 2009a.

PINTO, Maria Raquel Barreto. Tempo e espaço escolares: o (des)confinamento da infância. In: Reunião anual da ANPEd, 28., 2005, Caxambu. Anais eletrônicos. Caxambu: ANPEd, 2005. Disponível em:

<http://www.anped.org.br/reunioes/28/textos/gt13/gt13423int.rtf>. Acesso em: 19 fev. 2009b.

ROSA, João Guimarães. Primeiras estórias. Nova Fronteira: Rio de Janeiro, 2005. SANT' ANA, Ruth Bernardes de. Rotina e experiências formativas na pré-escola. In:

Reunião Anual da ANPEd, 27., 2004, Caxambu. Anais eletrônicos. Caxambu: ANPEd, 2004. Disponível em: <http://www.anped.org.br/reunioes/27/gt07/t077.pdf>. Acesso em: 09 fev. 2009.

SKLIAR, Carlos. Sobre a temporalidade do outro e da mesmidade - notas para um tempo (excessivamente) presente. In: SKLIAR, Carlos. Pedagogia (improvável) da diferença: e se o outro não estivesse aí? Rio de Janeiro: DP\&A, 2003. p. 37-64.

VIEIRA, Marina Tucunduva B. Porto. Associação casa da criança de santos na primeira república: concepções de infância. In: Reunião Anual da ANPEd, 28., 2005, Caxambu.

Anais eletrônicos. Caxambu: ANPEd, 2005. Disponível em:

<http://www.anped.org.br/reunioes/28/inicio.htm>. Acesso em: 19 jul. 2010.

recebido em: 05.09.2017

aprovado em: 22.03 .2018 